
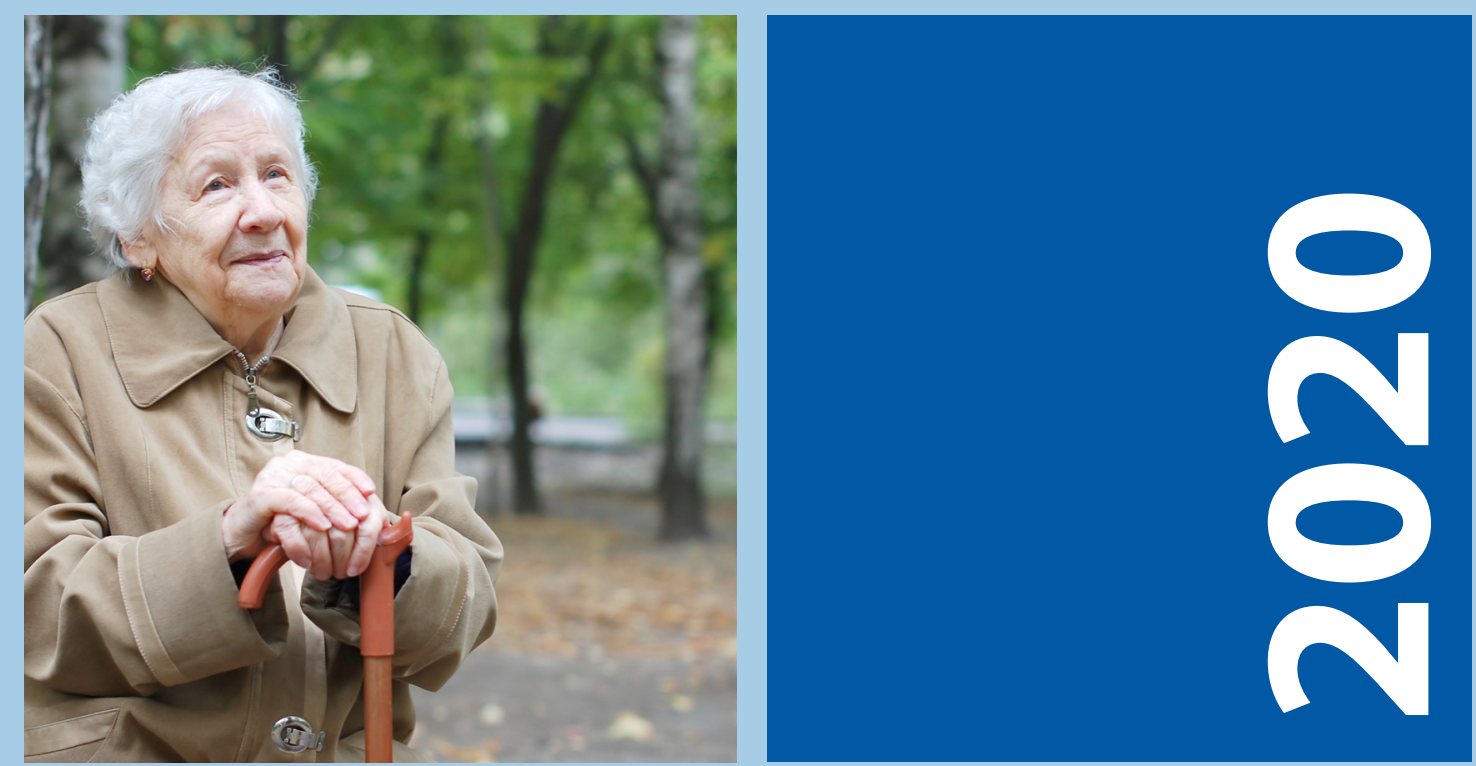

Loneliness and social isolation in the COVID-19 Pandemic among the over 70s: Data from The Irish Longitudinal Study on Ageing (TILDA) and ALONE

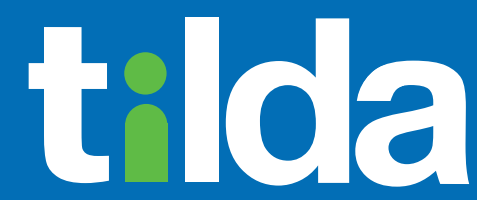

Staidéar Fadaimseartha na hÉireann um Dhul in Aois

The Irish Longitudinal Study on Ageing 


\section{Loneliness and social isolation in the COVID-19 Pandemic among the over 70s: Data from The Irish Longitudinal Study on Ageing (TILDA) and ALONE}

Mark Ward, Christine McGarrigle, Ann Hever, Paul O’Mahoney, Seán Moynihan,

Gráinne Loughran and Rose Anne Kenny

The Irish Longitudinal Study on Ageing

ALONE

July 2020
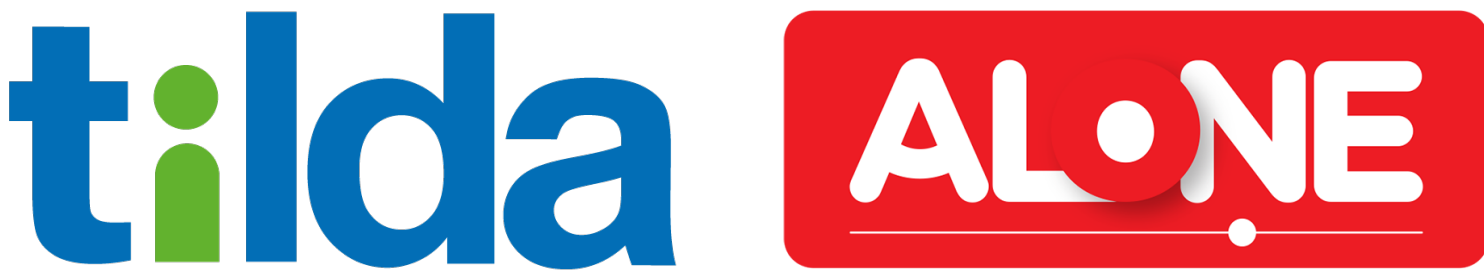
Copyright $(\odot$ The Irish Longitudinal Study on Ageing 2020

The Irish Longitudinal Study on Ageing

Trinity College Dublin

Dublin 2

Tel: +35318962509

Email: tilda@tcd.ie

Website: www.tilda.ie

ISBN: 978-1-907894-33-6

https://www.doi.org/10.38018/TildaRe.2020-07 


\section{Acknowledgements}

We would like to acknowledge the vision and commitment of our study funders, The Department of Health with support from the Health Research Board; The Atlantic Philanthropies and Irish Life plc. We would like to state that any views expressed in this report are not necessarily those of the Department of Health or of the Minister for Health. We would also like to thank the TILDA participants without whom this research would not be possible. 


\section{Contents}

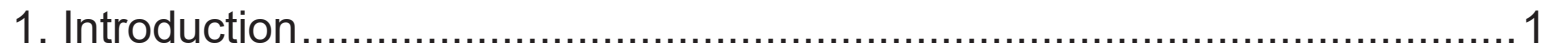

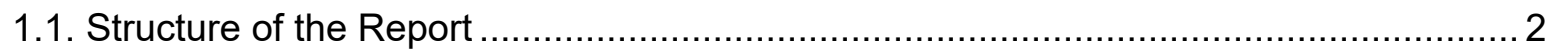

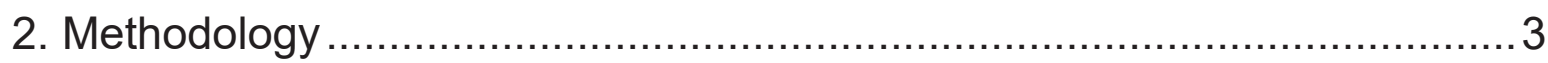

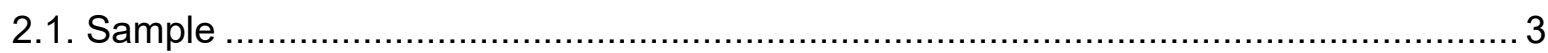

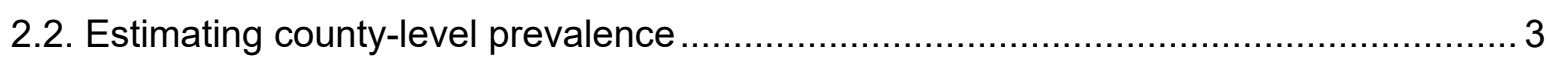

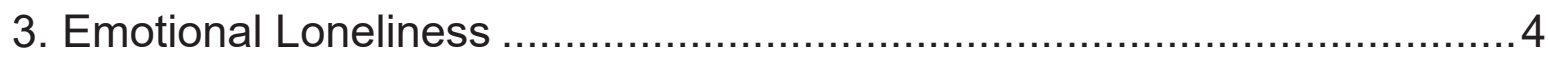

3.1. Sociodemographic characteristics by loneliness ................................................ 5

3.2. Loneliness and indicators of health and psychological wellbeing ............................ 7

3.3. County level population prevalence estimates of loneliness ..................................

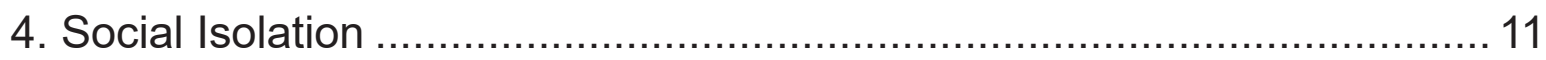

4.1. Sociodemographic characteristics by social isolation............................................. 12

4.2. Social isolation and indicators of health and psychological wellbeing...................... 13

4.3. County level population prevalence estimates of social isolation............................ 14

5. ALONE data on the impact of the COVID-19 Pandemic ....................... 16

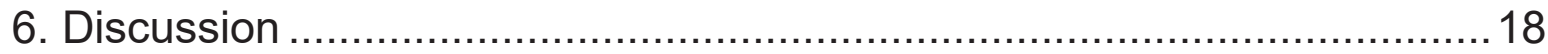

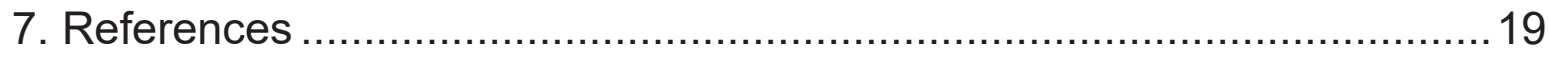




\section{Key Findings}

- $71 \%$ of older adults hardly ever or never feel lonely; less than a quarter $(24.0 \%)$ feel lonely some of the time; and $5 \%$ often feel lonely.

- Of those living alone, $31 \%$ are least lonely, $32 \%$ moderately and $37 \%$ most lonely.

- Of those living with others, $49 \%$ are least lonely, $30 \%$ moderately and $21 \%$ most lonely.

- There are no differences between rural and urban adults aged 70+ in the levels of loneliness reported, however men who live alone tend to be lonelier than women who live alone.

- Loneliness was also associated with more depressive symptoms.

- The majority (63\%) of adults aged $70+$ feel most or moderately socially integrated, meaning they have regular social contacts.

- Men are more likely than women to be in the most integrated group ( $24.6 \%$ vs. $18.9 \%)$.

- Both loneliness and social isolation are associated with a poorer quality of life, with loneliness a more important determinant.

- The ALONE COVID-19 helpline has received 24,529 calls to June 21 st.

- $54 \%$ of calls were from over 70 s, the cohort advised to 'cocoon'

- $76 \%$ of callers to the helpline are living alone

- ALONE has seen a rise during the pandemic of callers reporting negative emotions, including suicidal ideation

- Calls indicate that physical health is the highest area of need for older people with chronic illnesses such as COPD and diabetes having greater impact on quality of life during cocooning than previously

- There has been an increase in callers who are putting off medical treatment or examination, including after falls

- Current measures such as social distancing and cocooning in response to the COVID-19 pandemic is likely to increase level of loneliness and social isolation. This may have a negative effect on the wellbeing of older adults. Public policies should be developed to ensure that these issues are addressed. 


\section{Introduction}

This joint report from TILDA and ALONE examines the issues of loneliness and social isolation with specific reference to the COVID-19 pandemic in Ireland. Measures introduced to curtail the spread of COVID-19, including social distancing, self-isolation and 'cocooning' among the over 70s, have meant disruption to familiar routines and social interactions, particularly among older adults.

Loneliness is a complex construct with many definitions. In the TILDA data, we describe different types of loneliness, and measure emotional loneliness and social isolation using internationally validated instruments. In this report we make a clear distinction between what are termed emotional loneliness and social isolation. Loneliness is the subjective assessment of an individual's satisfaction with their social relationships whereas social isolation is a measure of the size of social network.

Positive social relationships and interactions are important to personal wellbeing at all ages. Strong social ties may protect us from emotional distress, cognitive decline, and physical disability $(1,2)$. By the same token, loneliness and social isolation can be harmful to our physical and psychological wellbeing $(1,3-5)$.

Factors which increase the risk of loneliness and social isolation include functional limitations, widowhood, lower income, and lower levels of education (5,6). A report on loneliness and social isolation published by TILDA in 2019 found that both loneliness and social isolation are associated with poorer quality of life and other measures of wellbeing (5). Loneliness is not a necessary feature of ageing, however. While some studies find higher levels of loneliness in older age, others do not show this association (4). A large majority of TILDA participants (over $70 \%$ ) report that they never or rarely feel lonely; $5 \%$ report feeling lonely often. It is important to recognise the resilience among Ireland's older population, and that older adults are active participants in and contributors to society in a variety of ways. The COVID-19 pandemic, however, has made it more difficult to maintain regular connections, and may be expected to contribute to a rise in loneliness and social isolation among older adults.

Formal (e.g. churches, sporting and voluntary organisation) and informal (e.g. attending films, classes, lectures, concerts eating out, exercising) social participation can protect individuals from loneliness and social isolation. Regular formal and informal forms of 
social participation have been suspended due to restrictions in place due to COVID-19. Measures such as social distancing and cocooning have increased public awareness and discussion of loneliness and social isolation among all age groups, but particularly older adults. Loneliness was considered an important issue for public health even before the pandemic; evidence of its rise since the introduction of measures to curtail the spread of COVID-19 is provided by data from ALONE.

These measures may particularly impact those who previously relied on social engagement with people outside of their immediate family, for example the widowed and those without children or close relatives. We suspect that current physical distancing and social isolation measures will be most keenly felt by those who rely on community or church-based social participation and engagement. A planned research project, led by TILDA and with the collaboration of ALONE and others, will investigate and document the impact of the COVID-19 pandemic on the health and general wellbeing of older adults. This report offers some background to that future project, reviewing data on loneliness among the over 70s (those advised to 'cocoon') from Wave 5 of TILDA, and current data from ALONE gathered since the beginning of the pandemic and introduction of measures to curtail it in Ireland.

\subsection{Structure of the Report}

Following a description of the methodology employed by TILDA, this report is organised as follows: in Chapter 1 we describe loneliness among adults aged 70 years and older in Ireland using the UCLA loneliness scale, and we examine differences in loneliness according to a number of sociodemographic characteristics. Estimates of the prevalence of Ioneliness in each county are also reported. This Chapter concludes with a description of the association between loneliness, health, and psychological wellbeing indicators.

The second Chapter is focused on social integration and isolation measured using the Berkman-Syme Social Network Index (SNI) (7). In this Chapter we describe social isolation and how it relates to sociodemographic characteristics and health and psychological wellbeing. Estimates of the prevalence of social isolation in each county are also reported.

The third Chapter provides data from ALONE, gathered since the introduction of measures to curtail the spread of COVID-19 pandemic, which show the impact of the pandemic, particularly 'cocooning' measures, among the older population.

Concluding discussion draws out the implications of the ALONE data and describes the planned project to document the effects of the COVID-19 pandemic on older adults in Ireland. 


\section{Methodology}

The Irish Longitudinal Study on Ageing (TILDA) is a prospective, nationally-representative study of community-dwelling older adults in the Republic of Ireland. Since 2009, TILDA has collected information every two years on all aspects of health, economic and social circumstances from community-dwelling people aged 50 and over. Participants were selected using multi-stage stratified random sampling whereby 640 geographical areas, stratified by socio-economic characteristics, were selected, followed by 40 households within each area. The Irish GeoDirectory listing of all residential addresses provided the sampling frame. The first Wave of data collection was conducted between October 2009 and July 2011 and a total of 8,504 participants were recruited. This represents 1 in 156 people aged 50 and over in Ireland.

TILDA collects data from participants in three ways: computer-assisted personal interview (CAPI) administered by trained social interviewers in the participants' own homes; a selfcompletion questionnaire (SCQ) completed privately by the participant and designed for the collection of more sensitive information such as alcohol use and relationships; and a health assessment carried out by research nurses at Waves 1 and 3 . The fifth wave of data collection was completed in December 2018 and TILDA will begin collecting data for Wave 6 in 2020. The response rate at Wave 1 was $62 \%$.

To account for systematic differences in participation among different sub-groups and to ensure that any estimates derived from the sample are representative of the wider population, appropriate survey weights are applied to the data. These survey weights were estimated based on age, sex and educational attainment. Further details on all aspects of the methodology used in TILDA are available elsewhere (9-12).

\subsection{Sample}

The sample includes 2,009 TILDA participants aged 70 years and older who participated in Wave 5 between January 2018 and December 2018.

\subsection{Estimating county-level prevalence}

The estimated numbers of people aged 70 and over presented by county are calculated from the percentage of those who are lonely and socially isolated for each county in TILDA data, expressed as a proportion of county populations based on Census 2016 (which reported a total of 426,331 people over 70 living in Ireland). In all cases, population numbers have been rounded to the nearest 100 . 


\section{Emotional Loneliness}

Emotional loneliness is the subjective assessment of an individual's satisfaction with the quality of their social relationships. It is the feeling of loneliness an individual experiences and while most often understood to be the emotion association with social isolation (13), loneliness can also be present among highly socially integrated individuals (14).

TILDA has two methods to look at frequency of loneliness. TILDA asks participants a separate single question about their feeling of loneliness as part of the self-completion questionnaire ("How often do you feel lonely?"), show that $70.7 \%$ (95\% Cl: 68.3-73.1) of older adults hardly ever or never feel lonely; $24.0 \%$ (95\% Cl: $21.9-26.3)$ feel lonely some of the time; and $5.3 \%(95 \% \mathrm{Cl}: 4.2-6.6)$ often feel lonely.

As well as the single item question on loneliness, TILDA also uses a modified 5-item UCLA Loneliness scale. the University of California-Los Angeles (UCLA) Loneliness scale (15). This measurement tool consists of five items:

- How often do you feel you lack companionship?

- How often do you feel left out?

- How often do you feel isolated from others?

- How often do you feel in tune with the people around you?

- How often do you feel lonely?

Each question has three response options (hardly ever or never $=0$, some of the time $=1$, often $=2$ ). Responses to the five items are summed, resulting in an overall score ranging from 0 (not lonely) to 10 (extremely lonely).

We now use scores from that scale to describe loneliness among adults aged 70 years and older. Figure 3.1 shows the distribution of loneliness across the range of possible UCLA loneliness scores with higher scores indicating more loneliness. Based on this multi-item indicator, $42.1 \%$ (95\% Cl: $40.2-45.5)$ of older adults' report that they are not at all lonely (score of zero) and very few report the highest levels of loneliness. The average loneliness score is 1.6 and the median is 1.0 . 
Figure 3.1 Distribution of UCLA loneliness scores

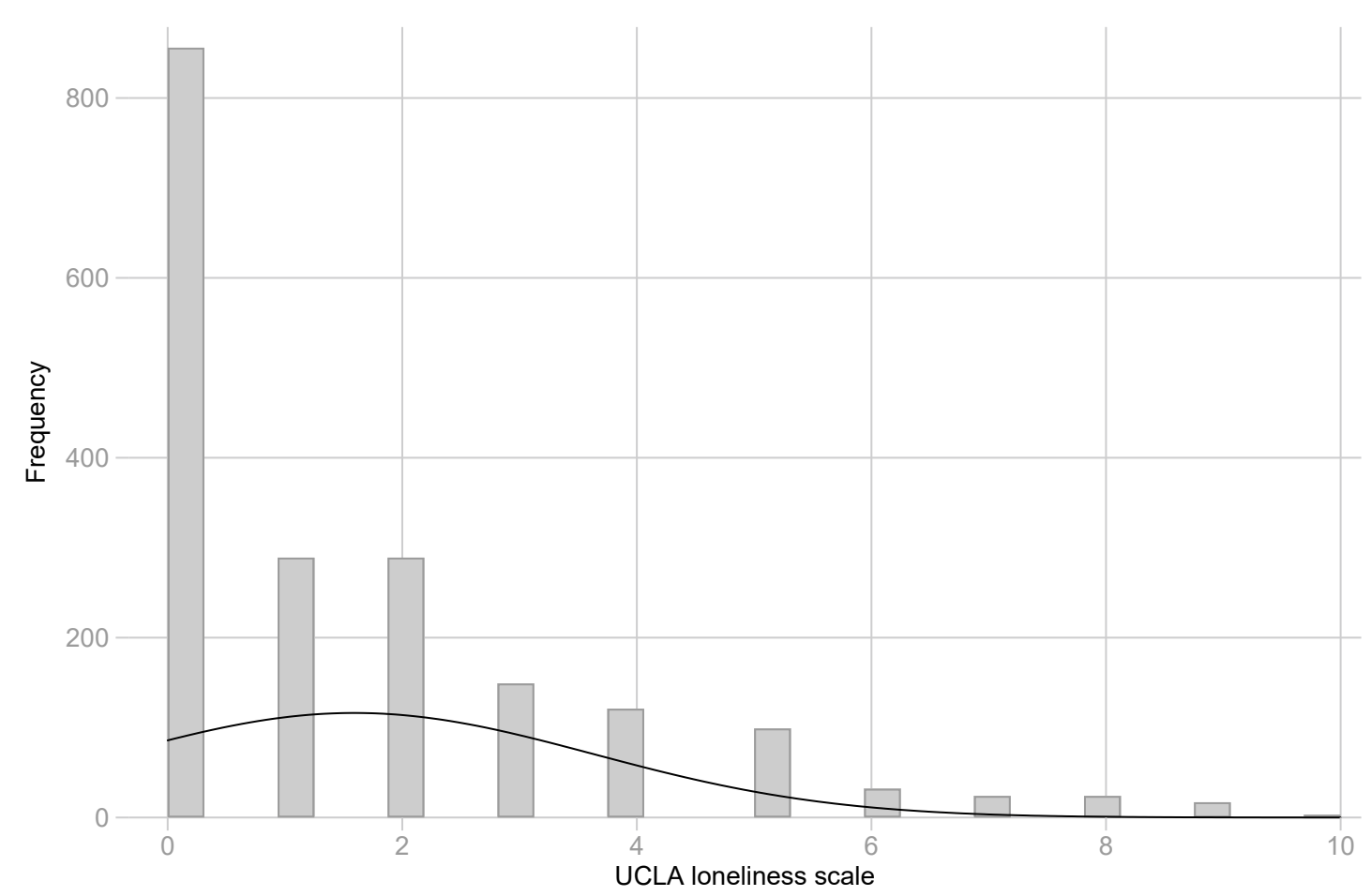

It is clear from Figure 3.1 that UCLA loneliness scores are asymmetrical; so, for the remainder of the analysis, we divide the scores into three groups (tertiles) - those with the lowest third of scores, the middle third, and the highest third. The first of these three groups include the least lonely participants $(42.8 \%, 95 \% \mathrm{Cl}: 40.2-45.5)$ who have a scores of zero on the UCLA loneliness scale. The middle group (30.9\%, $95 \% \mathrm{Cl}: 28.5-33.4)$ score either one or two, while the loneliest group $(26.3 \%, 95 \% \mathrm{Cl}: 24.0-28.8)$ score between three and ten.

\subsection{Sociodemographic characteristics by loneliness}

Table 3.1 shows the percentage of adults aged 70 years and older in each of the three loneliness groups (least, moderate, most lonely), according to their sociodemographic characteristic. Those with third level education (47.3\%, 95\% Cl: 42.7-52.0) are more likely than those with primary level education $(36.8 \%, 95 \% \mathrm{Cl}: 32.5-42.2)$ to be in the least lonely group. Of those living alone $37.0 \%$ (95\% Cl: 32.3-41.8) are among the most lonely compared to $21.0 \%$ (95\% Cl: $18.5-23.8)$ of those who live with other individuals. There are no differences between rural and urban adults aged $70+$ in the levels of loneliness reported. 
Table 3.1 Distribution of loneliness by key socio-demographic characteristics

\begin{tabular}{|c|c|c|c|c|c|c|}
\hline & \multicolumn{2}{|c|}{ Least Lonely } & \multicolumn{2}{|c|}{ Moderately Lonely } & \multicolumn{2}{|c|}{ Most Lonely } \\
\hline & $\%$ & $95 \% \mathrm{Cl}$ & $\%$ & $95 \% \mathrm{Cl}$ & $\%$ & $95 \% \mathrm{Cl}$ \\
\hline \multicolumn{7}{|l|}{ Gender } \\
\hline Male & 44.7 & $(41.1,48.3)$ & 31.7 & $(28.3,35.4)$ & 23.6 & $(20.4,27.0)$ \\
\hline Female & 41.2 & $(37.6,44.8)$ & 30.2 & $(27.0,33.6)$ & 28.7 & $(25.4,32.1)$ \\
\hline \multicolumn{7}{|l|}{ Education } \\
\hline Primary/none & 36.8 & $(32.5,41.2)$ & 33.9 & $(29.6,38.4)$ & 29.4 & $(25.3,33.8)$ \\
\hline Secondary & 45.9 & $(41.9,49.8)$ & 29.9 & $(26.4,33.6)$ & 24.3 & $(20.8,28.1)$ \\
\hline Third/higher & 47.3 & $(42.7,52.0)$ & 27.7 & $(24.0,31.8)$ & 25.0 & $(21.1,29.3)$ \\
\hline \multicolumn{7}{|l|}{ Living status } \\
\hline Lives alone & 31.0 & $26.7,35.5$ & 32.1 & $27.7,36.8$ & 37.0 & $32.3,41.8$ \\
\hline Lives with others & 48.7 & $45.4,51.9$ & 30.3 & $27.6,33.2$ & 21.0 & $18.5,23.8$ \\
\hline \multicolumn{7}{|l|}{ Location } \\
\hline Dublin city or county & 47.4 & $(42.4,52.4)$ & 29.9 & $(25.5,34.7)$ & 22.8 & $(18.4,27.8)$ \\
\hline Another town or city & 41.0 & $(36.2,45.9)$ & 32.7 & $(28.0,37.8)$ & 26.3 & $(22.4,30.6)$ \\
\hline A rural area & 41.2 & $(37.2,45.3)$ & 30.1 & $(26.7,33.8)$ & 28.7 & $(25.0,32.7)$ \\
\hline Total & 42.8 & $(40.1,45.5)$ & 30.9 & $(28.5,33.4)$ & 26.3 & $(24.0,28.8)$ \\
\hline
\end{tabular}

Figure 3.2 shows that living alone is associated with greater loneliness for both men and women. Among those who live with others, there is a similar percentage of men and women in each loneliness group. However, the association between living alone and loneliness is clearest among men with living alone associated with greater loneliness. The picture among women who live alone is different with a similar percentage of women in each of the three loneliness groups. This all suggests that men who live alone tend to be lonelier than women in the same situation. 
Figure 3.2 Distribution of loneliness by sex and living status
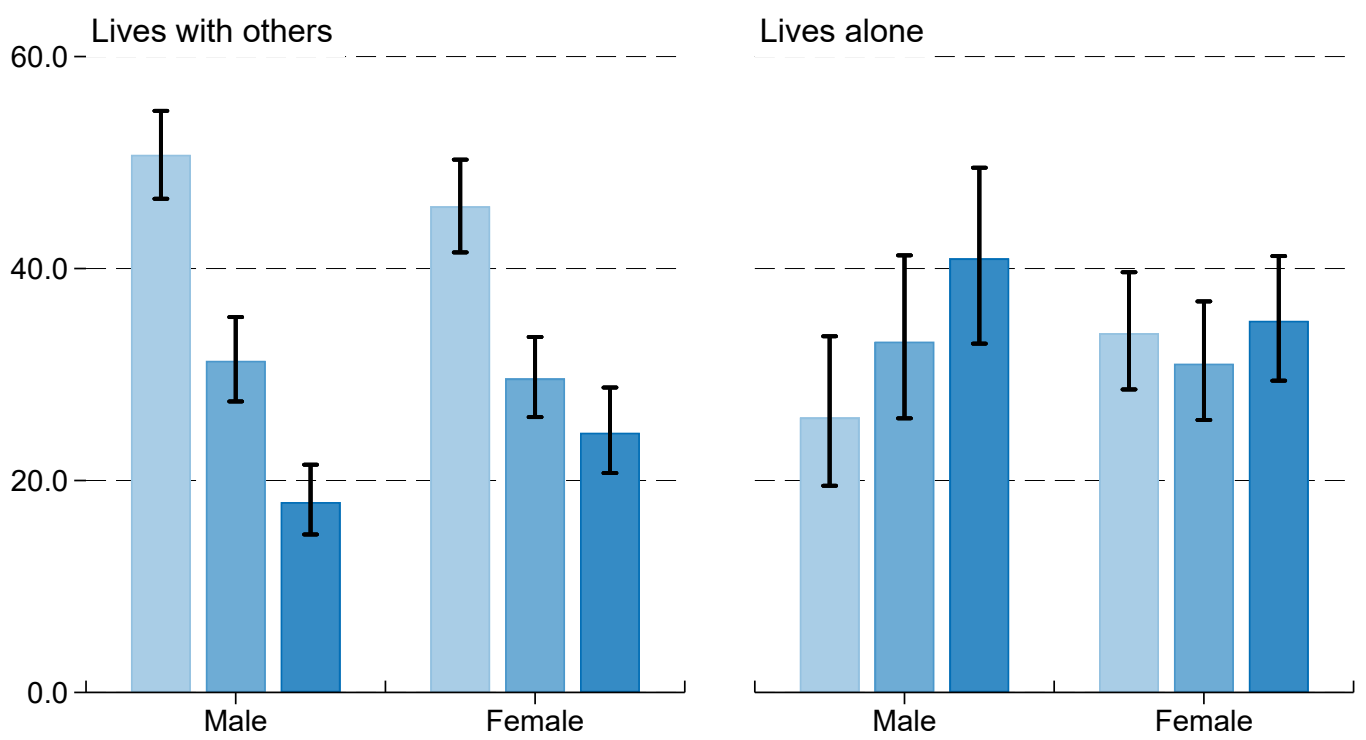

Least lonely

Moderately lonely

Most lonely

\subsection{Loneliness and indicators of health and psychological wellbeing}

In TILDA functional disability is measured as self-reported limitations in the activities of daily living (ADLs; help with walking across a room, dressing, bathing, eating, getting in and out of bed, and using the toilet) and instrumental activities of daily living (IADLs; preparing meals, shopping for groceries, making telephone calls, taking medications and managing money). The number of ADL limitations and IADL limitations was calculated and categorised as No limitations, at least one limitation. Two psychological wellbeing outcomes are examined. TILDA uses the 12-item self-report measurement, (CASP-12), to assess quality of life in Wave 4 (14). The scale covers the four domains considered to encompass quality of life (Table 3.1). The items included in CASP-12 consist of statements such as: 'I can do the things I want to do', 'I look forward to every day' and 'I feel that life is full of opportunities'. These statements are presented to participants in the SCQ and they are asked to indicate how often (often, sometimes, not often or never), they feel each statement applies to their life. Each item is summed to give an overall score (range 0 to 36) with higher scores denoting better quality of life. Depressive symptoms are measured using the 8-item Centre for Epidemiological Studies Depression (CES-D) scale. The CES-D8 is administered during the CAPI and measured the degree to which respondents have experienced a wide variety of depressive symptoms within the past week, with higher scores indicating increased depressive symptomology (19-21). We excluded the CES-D item that asked whether a respondent 'felt lonely' $(13,22)$. Each of the 7 items in this 
revised measure is measured on a 4-point scale, ranging from zero to three, leading to a maximum score of 21 with higher scores indicating more depressive symptoms.

Table 3.2 shows the distribution of loneliness according to key indicators of health and psychological wellbeing. There is a clear association between loneliness and self-rated health. More than half of adults aged $70+$ who report excellent or very good physical health are in the least lonely group (52.6\%, 95\% Cl: 48.6-56.5). Conversely, more than one-third of those who report fair or poor health are in the loneliest group $(38.2 \%, 95 \% \mathrm{Cl}$ : 32.4-44.4). This compared to less than one-fifth $(17.8 \%, 95 \% \mathrm{Cl}: 15.0-21.1)$ of those with excellent or very good self-rated health. Loneliness is also associated with the ADLs and IADLs. More than one-third of adults aged 70+ who have an ADL are in the loneliest group (38.4\%, 95\% Cl: 38.4-47.2). Among those who have at least one IADL, 44.6\% (95\% Cl: 36.3-53.3) are in the loneliest group.

There is also a clear association between loneliness and quality of life measured using the CASP-12 survey instrument. While the average quality of life score is 29.4 (95\% Cl: 29.129.7) among those in the least lonely group out of a maximum of 36 , the average score in the loneliest is 22.7 (95\% Cl: 22.1-23.3). Finally, the depressive symptoms score reported by participants in the loneliest group $(4.2,95 \% \mathrm{Cl}$ : 3.8-4.7) is almost fourfold higher than that found among the least lonely group (1.1, 95\% Cl: 0.9-1.2). This shows that loneliness is associated with much poorer quality of life and more depressive symptoms. 
Table 3.2. Distribution of loneliness by key health and psychological wellbeing indicators

\begin{tabular}{l|cc|cc|cc} 
& \multicolumn{2}{c}{ Least Lonely } & \multicolumn{3}{c}{ Moderately Lonely } & \multicolumn{2}{c}{ Most Lonely } \\
& $\%$ & $95 \% \mathrm{Cl}$ & $\%$ & $95 \% \mathrm{Cl}$ & $\%$ & $95 \% \mathrm{CI}$ \\
\hline $\begin{array}{l}\text { Self-rated health } \\
\text { Excellent/V. Good }\end{array}$ & 52.6 & $(48.6,56.5)$ & 29.6 & $(26.1,33.4)$ & 17.8 & $(15.0,21.1)$ \\
\hline Good & 39.0 & $(34.9,43.2)$ & 32.0 & $(28.2,36.2)$ & 29.0 & $(25.1,33.2)$ \\
\hline Fair/Poor & 30.5 & $(25.0,36.5)$ & 31.3 & $(26.0,37.2)$ & 38.2 & $(32.4,44.4)$ \\
\hline ADLs & & & & & & \\
None & 44.6 & $(41.8,47.5)$ & 30.8 & $(28.3,33.5)$ & 24.5 & $(22.2,27.0)$ \\
\hline At least one & 30.2 & $(23.2,38.3)$ & 31.4 & $(24.5,39.3)$ & 38.4 & $(30.2,47.2)$ \\
\hline IADLs & & & & & & \\
None & 44.7 & $(42.0,47.5)$ & 31.3 & $(28.8,34.0)$ & 24.0 & $(21.6,26.5)$ \\
\hline At least one & 27.7 & $(20.6,36.1)$ & 27.7 & $(20.6,36.1)$ & 44.6 & $(36.3,53.3)$ \\
\hline
\end{tabular}

CASP-12 Quality of life

Mean score $29.4 \quad(29.1,29.7) \quad 26.7 \quad(26.3,27.2) \quad 22.7$

$(22.1,23.3)$

CES-D depression score

\begin{tabular}{l|cccccc} 
Mean score & 1.1 & $(0.9,1.2)$ & 1.8 & $(1.6,2.0)$ & 4.2 & $(3.8,4.7)$ \\
Total & 42.8 & $(40.1,45.5)$ & 30.9 & $(28.5,33.4)$ & 26.3 & $(24.0,28.8)$ \\
\hline
\end{tabular}

\subsection{County-level population prevalence estimates of loneliness}

Finally, in this Chapter, we report estimates of the numbers of adults aged $70+$ in each county in the Republic of Ireland who are in the loneliest group as measured by the UCLA Ioneliness scale. As reported earlier, there were $26.3 \%$ (95\% Cl: $24.0-28.8)$ of adults in the loneliest group nationally. This translates to a total of over 110,000 (95\% Cl: $102300-$ $122800)$ thousand individuals. There was a good deal of variation between the county estimates. Longford had the smallest percentage of people in the loneliest $(9.5 \%, 95 \%$ Cl: 2.9-26.9) group while Leitrim had the highest at 50.5\% (95\% Cl: 23.8-76.8). However, caution is advised when interpreting these values as the confidence intervals are very wide due to the small number of participants in these groups. 
Table 3.3 Estimated number of adults aged 70+ years in the loneliest group by county (Sources: TILDA Wave 5; Central Statistics Office Statbank (Census 2016)

\begin{tabular}{|c|c|c|}
\hline & TILDA \% (95\% CI) & County count* estimate $(95 \% \mathrm{Cl})$ \\
\hline Carlow & $30.7 \%(13.7,55.2)$ & $1500(700,2700)$ \\
\hline Cavan & $20.9 \%(11.3,35.5)$ & $1500(800,2500)$ \\
\hline Clare & $24.2 \%(12.1,42.7)$ & $2800(1400,4900)$ \\
\hline Cork & $25.4 \%(18.5,33.8)$ & $12600(9200,16800)$ \\
\hline Donegal & $23.1 \%(14.8,34.2)$ & $3900(2500,5800)$ \\
\hline Dublin & $23.3 \%(18.8,28.4)$ & $26100(21100,31900)$ \\
\hline Galway & $34.4 \%(24.6,45.6)$ & $8100(5800,10700)$ \\
\hline Kerry & $30.0 \%(18.4,44.8)$ & $4900(3000,7400)$ \\
\hline Kildare & $23.8 \%(11.8,42.1)$ & $3300(1600,5800)$ \\
\hline Kilkenny & $19.7 \%(8.2,40.4)$ & $1900(800,3800)$ \\
\hline Laois & $28.5 \%(13.5,50.3)$ & $1800(900,3200)$ \\
\hline Leitrim & $50.5 \%(23.8,76.8)$ & $1800(900,2800)$ \\
\hline Limerick & $28.7 \%(19.9,39.6)$ & $5200(3600,7200)$ \\
\hline Longford & $9.5 \%(2.9,26.9)$ & $400(100,1000)$ \\
\hline Louth & $20.2 \%(9.5,37.8)$ & $2200(1000,4000)$ \\
\hline Mayo & $25.0 \%(16.1,36.5)$ & $3800(2500,5600)$ \\
\hline Meath & $28.3 \%(17.7,42.0)$ & $3800(2400,5600)$ \\
\hline Monaghan & $28.5 \%(18.4,41.5)$ & $1600(1000,2400)$ \\
\hline Offaly & $35.7 \%(18.4,57.7)$ & $2500(1300,4100)$ \\
\hline Roscommon & $34.1 \%(16.4,57.6)$ & $2500(1200,4200)$ \\
\hline Sligo & $16.4 \%(6.7,35.1)$ & $1200(500,2500)$ \\
\hline Tipperary & $26.0 \%(17.1,37.4)$ & $4300(2800,6200)$ \\
\hline Waterford & $32.6 \%(23.4,43.2)$ & $3800(2700,5000)$ \\
\hline Westmeath & $16.7 \%(7.6,32.8)$ & $1300(600,2500)$ \\
\hline Wexford & $31.3 \%(22.0,42.5)$ & $4600(3200,6200)$ \\
\hline Wicklow & $25.4 \%(13.8,42.0)$ & $3100(1700,5100)$ \\
\hline National average & $26.3 \%(24.0,28.8)$ & $112100(102300,122800)$ \\
\hline
\end{tabular}

* The estimated county-level counts have been rounded to the nearest 100 


\section{Social Isolation}

TILDA uses a measure of the size of an individual's social network to measure social isolation. The size of social networks is measured using the Berkman-Syme Social Network Index (SNI) (8). This index is scored on a 0-4 composite scale that captures four types of social connection: (1) marital status; (2) close ties with children, relatives and friends; (3) membership of a church group, and (4) membership of voluntary organisations. A score of 0-1 identifies individuals as 'most isolated', with a score of 4 indicating 'most integrated'. To aide their interpretability, these scores have been reversed so that higher scores indicate greater isolation.

In this section, we describe the distribution of social isolation using the Berkman-Syme Social Network Index (SNI) (7) described earlier. As shown in Figure 4.1, 21.5\% (95\% Cl: 19.7-23.5) of participants are in the most integrated group, $41.4 \%$ (95\% Cl: $39.0-43.7)$ are moderately integrated, $26.2 \%$ (95\% Cl: $24.1-28.4)$ are moderately isolated, and $10.9 \%$ (95\% Cl: 9.3-12.7) are in the most isolated group.

Figure 4.1 Distribution of Social Network Index (SNI) scores (reverse coded so that higher scores indicate more socially isolated)

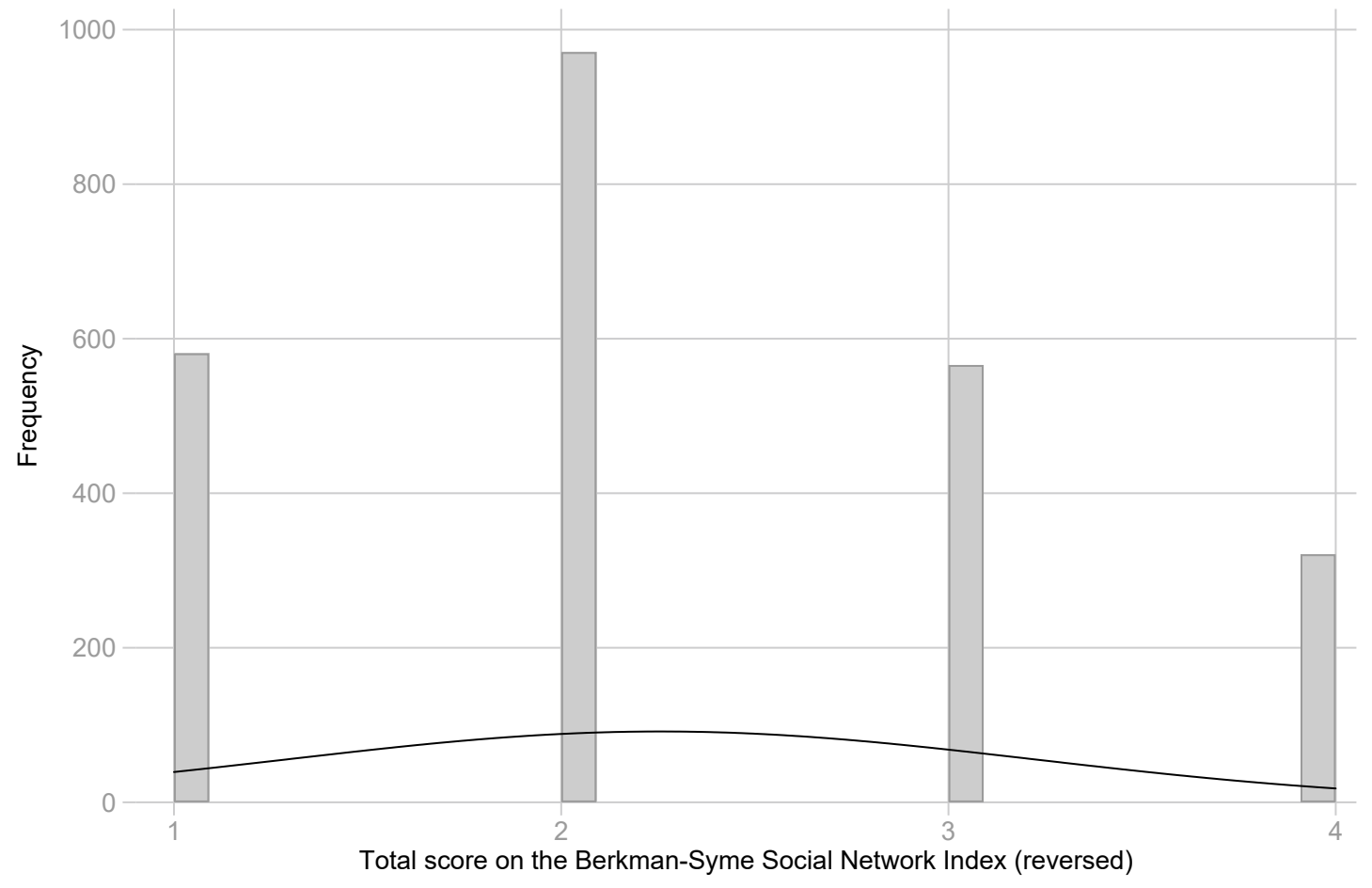




\subsection{Sociodemographic characteristics by social isolation}

Table 4.1 shows that while there is no difference in the percentage of men and women in the moderately and most isolated groups, men aged 70 years and older are more likely to be in the most integrated group $(24.6 \%$ Vs. $18.9 \%)$. There is a clear education gradient with higher levels of education associated with greater social integration. In terms of location, adults aged $70+$ who live in a town or city other than Dublin $(15.1 \%, 95 \% \mathrm{Cl}$ : 12.0-18.9) are more isolated than those who lived in Dublin City or County $(8.2 \%, 95 \% \mathrm{Cl}$ : 5.9-11.2).

Table 4.1 Distribution of social isolation by key sociodemographic characteristics

\begin{tabular}{|c|c|c|c|c|c|c|c|c|}
\hline & \multicolumn{2}{|c|}{ Most Integrated } & \multicolumn{2}{|c|}{$\begin{array}{l}\text { Moderately } \\
\text { Integrated }\end{array}$} & \multicolumn{2}{|c|}{$\begin{array}{l}\text { Moderately } \\
\text { Isolated }\end{array}$} & \multicolumn{2}{|c|}{ Most Isolated } \\
\hline & $\%$ & $95 \% \mathrm{Cl}$ & $\%$ & $95 \% \mathrm{Cl}$ & $\%$ & $95 \% \mathrm{Cl}$ & $\%$ & $95 \% \mathrm{Cl}$ \\
\hline \multicolumn{9}{|l|}{ Gender } \\
\hline Male & 24.6 & $(22.0,27.4)$ & 39.2 & $(36.1,42.4)$ & 26.6 & $(23.6,29.8)$ & 9.6 & $(7.6,12.1)$ \\
\hline Female & 18.9 & $(16.7,21.3)$ & 43.2 & $(40.1,46.5)$ & 25.8 & $(23.0,28.9)$ & 12.0 & $(9.9,14.6)$ \\
\hline \multicolumn{9}{|l|}{ Education } \\
\hline Primary/none & 16.0 & $(13.4,19.1)$ & 39.4 & $(35.4,43.6)$ & 29.1 & $(25.5,33.1)$ & 15.4 & $(12.5,18.8)$ \\
\hline Secondary & 23.6 & $(20.7,26.8)$ & 41.5 & $(37.9,45.2)$ & 25.6 & $(22.4,29.2)$ & 9.2 & $(7.2,11.8)$ \\
\hline Third/higher & 28.2 & $(24.6,32.1)$ & 45.0 & $(40.7,49.3)$ & 21.3 & $(17.8,25.3)$ & 5.5 & $(3.8,7.9)$ \\
\hline \multicolumn{9}{|l|}{ Living status } \\
\hline Lives alone & & $\mathrm{N} / \mathrm{A}$ & 37.1 & $33.1,41.2$ & 40.5 & $36.3,44.8$ & 22.5 & $19.0,26.4$ \\
\hline $\begin{array}{l}\text { Lives with } \\
\text { others }\end{array}$ & 33.5 & $30.8,36.3$ & 43.8 & $41.0,46.5$ & 18.2 & $16.1,20.6$ & 4.5 & $3.2,6.3$ \\
\hline \multicolumn{9}{|l|}{ Location } \\
\hline $\begin{array}{l}\text { Dublin city or } \\
\text { county }\end{array}$ & 22.0 & $(18.1,26.4)$ & 45.2 & $(40.4,50.1)$ & 24.6 & $(20.6,29.2)$ & 8.2 & $(5.9,11.2)$ \\
\hline $\begin{array}{l}\text { Another town } \\
\text { or city }\end{array}$ & 21.8 & $(18.5,25.4)$ & 36.0 & $(32.0,40.2)$ & 27.1 & $(23.3,31.3)$ & 15.1 & $(12.0,18.9)$ \\
\hline A rural area & 21.1 & $(18.4,24.0)$ & 43.2 & $(39.6,46.7)$ & 26.4 & $(23.4,29.7)$ & 9.4 & $(7.2,12.2)$ \\
\hline Total & 21.5 & $(19.7,23.5)$ & 41.4 & $(39.0,43.7)$ & 26.2 & $(24.1,28.4)$ & 10.9 & $(9.3,12.7)$ \\
\hline
\end{tabular}

As shown in Figure 4.2, a similar pattern of social isolation is found between men and women aged 70 years and older who live with other people. Among these groups, a majority of both men and women are considered moderately or mostly socially integrated while less than one-third are socially isolated. There are clear differences in the pattern of 
social isolation between men and women who live alone. While the largest percentage of women who live alone are moderately integrated, men who live alone are most likely to be moderately isolated.

Figure 4.2 Distribution of social isolation by sex and living status
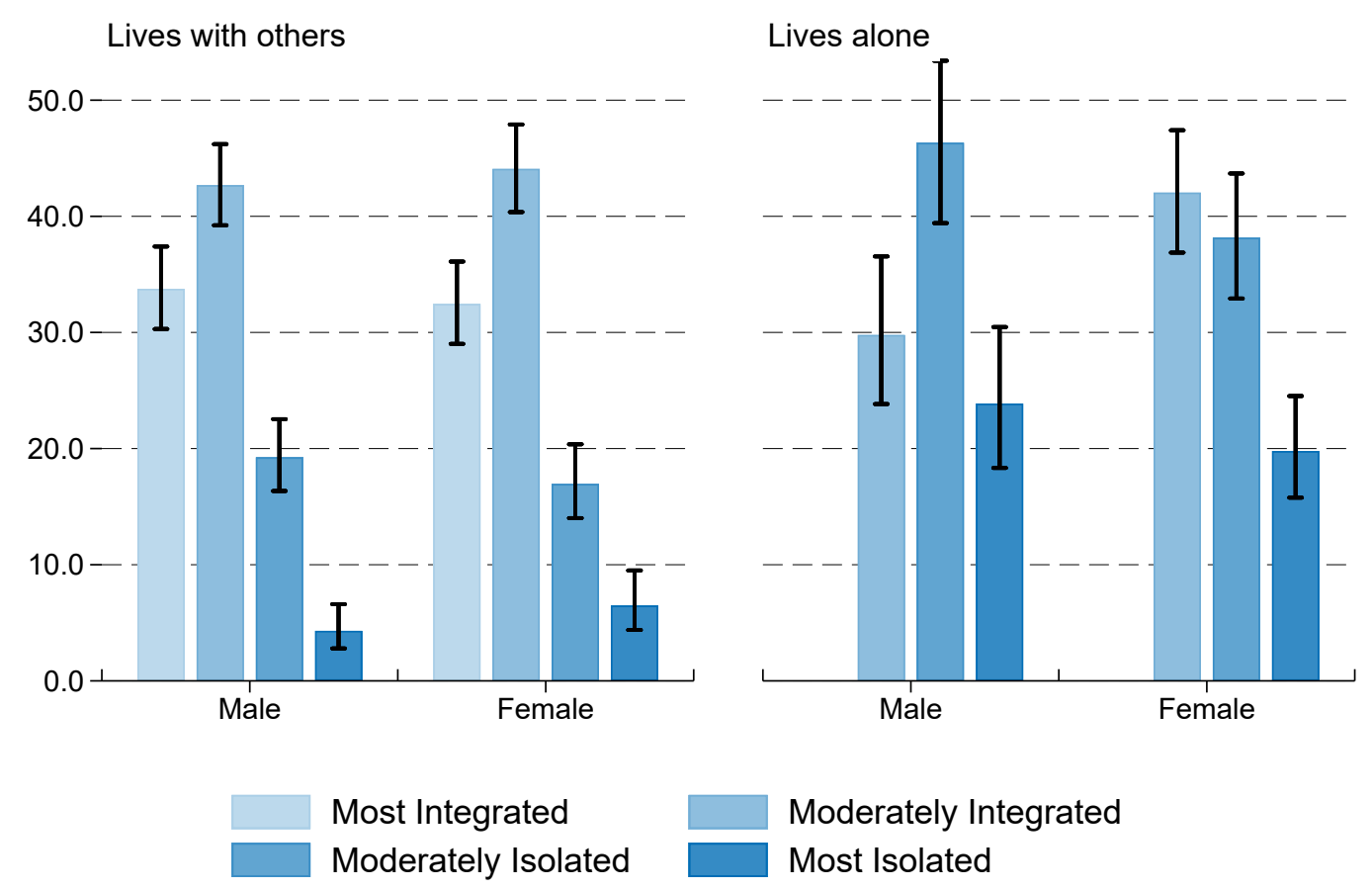

\subsection{Social isolation and indicators of health and psychological wellbeing}

Similar to loneliness, social isolation is clearly related to poorer physical and psychological health. As shown in Table 4.2, adults aged 70 years and older who have fair or poor selfrated physical health $(21.2 \%, 95 \% \mathrm{Cl}: 17.0-26.2)$ are significantly more likely than those with good $(105 . \%, 95 \% \mathrm{Cl}: 8.1-13.4)$ or excellent/very good health $(5.6 \%, 95 \% \mathrm{Cl}: 4.1-7.7)$ to be in the most isolated group. Older adults who have at least one ADL and those who report one or more IADLs are also significantly more likely to be socially isolated. Social isolation is also associated with poorer quality of life although the association is weaker than that found between loneliness and quality of life. Finally, adults aged $70+$ who are in the most socially isolated group $(3.9,95 \% \mathrm{Cl}: 3.0-4.8)$ report a significantly higher number of depressive symptoms compared to those in the most integrated group (1.4, 95\% Cl: $1.2-$ 1.6).

These results clearly show that social isolation is association with a wide range of poorer health measures, while older adults who are most socially integrated tend to have better physical and mental health as well as better quality of life. 
Table 4.2. Distribution of social isolation by key health and psychological wellbeing indicators

\begin{tabular}{|c|c|c|c|c|c|c|c|c|}
\hline & \multicolumn{2}{|c|}{ Most Integrated } & \multicolumn{2}{|c|}{$\begin{array}{l}\text { Moderately } \\
\text { Integrated }\end{array}$} & \multicolumn{2}{|c|}{$\begin{array}{l}\text { Moderately } \\
\text { Isolated }\end{array}$} & \multicolumn{2}{|c|}{ Most Isolated } \\
\hline & $\%$ & $95 \% \mathrm{Cl}$ & $\%$ & $95 \% \mathrm{Cl}$ & $\%$ & $95 \% \mathrm{Cl}$ & $\%$ & $95 \% \mathrm{Cl}$ \\
\hline \multicolumn{9}{|l|}{$\begin{array}{l}\text { Self-rated } \\
\text { health }\end{array}$} \\
\hline $\begin{array}{l}\text { Excellent/V. } \\
\text { Good }\end{array}$ & 28.1 & $(25.1,31.3)$ & 44.9 & $(41.4,48.5)$ & 21.4 & $(18.4,24.6)$ & 5.6 & $(4.1,7.7)$ \\
\hline Good & 20.3 & $(17.5,23.3)$ & 39.4 & $35.7,43.2)$ & 29.9 & $(26.5,33.6)$ & 10.5 & $(8.1,13.4)$ \\
\hline Fair/Poor & 12.3 & $(9.5,15.7)$ & 38.8 & $(33.7,44.1)$ & 27.7 & $(23.4,32.5)$ & 21.2 & $(17.0,26.2)$ \\
\hline \multicolumn{9}{|l|}{ ADLs } \\
\hline None & 23.0 & $(20.9,25.2)$ & 42.8 & $(40.2,45.3)$ & 25.7 & $(23.5,28.1)$ & 8.6 & $(7.0,10.4)$ \\
\hline At least one & 13.0 & $(9.4,17.5)$ & 33.3 & $(27.6,39.5)$ & 29.0 & $(23.2,35.6)$ & 24.7 & $(19.2,31.2)$ \\
\hline \multicolumn{9}{|l|}{ IADLs } \\
\hline None & 23.4 & $(21.4,25.6)$ & 43.2 & $(40.7,45.8)$ & 25.0 & $(22.8,27.3)$ & 8.4 & $(6.9,10.1)$ \\
\hline At least one & 9.1 & $(6.0,13.6)$ & 29.3 & $(23.5,36.0)$ & 34.0 & $(27.6,41.1)$ & 27.6 & $(21.4,34.8)$ \\
\hline \multicolumn{9}{|c|}{ CASP-12 Quality of life } \\
\hline (Mean score & 28.7 & $(28.2,29.1)$ & 27.1 & $(26.7,27.6)$ & 25.7 & $(25.0,26.4)$ & 24.0 & $(23.0,25.1)$ \\
\hline \multicolumn{9}{|c|}{ CES-D depression score } \\
\hline Mean score & 1.4 & $(1.2,1.6)$ & 2.0 & $(1.8,2.2)$ & 2.5 & $(2.2,2.9)$ & 3.9 & $(3.0,4.8)$ \\
\hline Total & 21.5 & $(19.7,23.5)$ & 41.4 & $(39.0,43.7)$ & 26.2 & $(24.1,28.4)$ & 10.9 & $(9.3,12.7)$ \\
\hline
\end{tabular}

\subsection{County-level population prevalence estimates of social isolation}

Table 4.3 shows the percentage of adults aged 70 years and older in each county who were moderately or most socially isolated groups. Overall, $37.1 \%(95 \% \mathrm{Cl}: 34.7,39.6)$ of participants were in one of these two groups and therefore considered isolated. This translates to 158,200 (95\% Cl: 147900-168800) individuals. Westmeath had the lowest proportion of isolated adults aged 70 years $(18.8 \%, 95 \% \mathrm{Cl}$ : 10.3-32.0) and older which translates to 1,400 (95\% Cl: $800-2400)$ individuals. The highest percentage of isolated over 70 s were found in Wicklow $(57.4 \%, 95 \% \mathrm{Cl}$ : 41.6-71.9). This represents 7,000 individuals (95\% Cl: 5100-8700). 
Table 4.3 Estimated number of adults aged 70+ years in the moderate and most socially isolated group by county (Sources: TILDA Wave 5; CSO Statbank (Census 2016))

\begin{tabular}{|c|c|c|}
\hline & TILDA \% (95\% CI) & County count ${ }^{*}$ estimate $(95 \% \mathrm{Cl})$ \\
\hline Carlow & $30.7 \%(13.7,55.2)$ & $1500(700,2700)$ \\
\hline Cavan & $20.9 \%(11.3,35.5)$ & $1500(800,2500)$ \\
\hline Clare & $24.2 \%(12.1,42.7)$ & $2800(1400,4900)$ \\
\hline Cork & $25.4 \%(18.5,33.8)$ & $12600(9200,16800)$ \\
\hline Donegal & $23.1 \%(14.8,34.2)$ & $3900(2500,5800)$ \\
\hline Dublin & $23.3 \%(18.8,28.4)$ & $26100(21100,31900)$ \\
\hline Galway & $34.4 \%(24.6,45.6)$ & $8100(5800,10700)$ \\
\hline Kerry & $30.0 \%(18.4,44.8)$ & $4900(3000,7400)$ \\
\hline Kildare & $23.8 \%(11.8,42.1)$ & $3300(1600,5800)$ \\
\hline Kilkenny & $19.7 \%(8.2,40.4)$ & $1900(800,3800)$ \\
\hline Laois & $28.5 \%(13.5,50.3)$ & $1800(900,3200)$ \\
\hline Leitrim & $50.5 \%(23.8,76.8)$ & $1800(900,2800)$ \\
\hline Limerick & $28.7 \%(19.9,39.6)$ & $5200(3600,7200)$ \\
\hline Longford & $9.5 \%(2.9,26.9)$ & $400(100,1000)$ \\
\hline Louth & $20.2 \%(9.5,37.8)$ & $2200(1000,4000)$ \\
\hline Mayo & $25.0 \%(16.1,36.5)$ & $3800(2500,5600)$ \\
\hline Meath & $28.3 \%(17.7,42.0)$ & $3800(2400,5600)$ \\
\hline Monaghan & $28.5 \%(18.4,41.5)$ & $1600(1000,2400)$ \\
\hline Offaly & $35.7 \%(18.4,57.7)$ & $2500(1300,4100)$ \\
\hline Roscommon & $34.1 \%(16.4,57.6)$ & $2500(1200,4200)$ \\
\hline Sligo & $16.4 \%(6.7,35.1)$ & $1200(500,2500)$ \\
\hline Tipperary & $26.0 \%(17.1,37.4)$ & $4300(2800,6200)$ \\
\hline Waterford & $32.6 \%(23.4,43.2)$ & $3800(2700,5000)$ \\
\hline Westmeath & $16.7 \%(7.6,32.8)$ & $1300(600,2500)$ \\
\hline Wexford & $31.3 \%(22.0,42.5)$ & $4600(3200,6200)$ \\
\hline Wicklow & $25.4 \%(13.8,42.0)$ & $3100(1700,5100)$ \\
\hline National average & $26.3 \%(24.0,28.8)$ & $112100(102300,122800)$ \\
\hline
\end{tabular}

* The estimated county-level counts have been rounded to the nearest 100 


\section{ALONE data on the impact of the COVID-19 Pandemic}

ALONE provides a range of services and coordinates with state and other community agencies, to address the problem of loneliness throughout Ireland. In 2018, ALONE collaborated in the establishment of the Loneliness Task Force 'to coordinate a response to the epidemic of loneliness and social isolation in Ireland'. The remit of the Taskforce is 'to increase awareness about the issue and to produce a set of recommendations for Government, state agencies and all policy makers'. (https://lonelinesstaskforce.com/). ALONE operates a nationwide befriending and Support service, whereby volunteers regularly visit and check in with their older person. ALONE also maintains a Vulnerable Adults List who receive an enhanced level of contact and support. ALONE also offers support coordination, support and telephone befriending services and social prescribing.

In response to the COVID-19 pandemic, ALONE established a dedicated helpline (0818 222 024), and partnered with the government's Community Call Forum, which aims to provide supports or services to any vulnerable person who needs them (https://communitycall-covid-19-geohive.hub.arcgis.com/). ALONE has received 24, 529 calls to the national support line since March 9th, covering a variety of issues, from clarification of government guidelines to difficulties with social distancing or cocooning.

Adapting to the restrictions introduced in response to the COVID-19 crisis, the befriending and support service has continued remotely; volunteers now phone, and send regular texts to older people with short health and wellbeing tips and reminders to make contact if they are feeling lonely, down or in need of practical supports. ALONE has completed 1,056 Technology prescriptions, including distributing 484 smartphones donated by Vodafone to vulnerable older adults with limited means of social interaction.

While the TILDA data show that most older people are not often lonely and appear quite resilient, the data from ALONE's helpline suggest that the pandemic has taken a toll on older people. Calls to the helpline since its establishment on March 9th, three days before the government announced the closure of the majority of public services, staff and volunteer calls to older people and those on the Vulnerable Adults List, show a rise in negative emotions during the COVID-19 pandemic, particularly stemming from cocooning. $29 \%$ of support plan objectives opened during this time were looking for longer term support in the area of Befriending and Emotional/ Mental Health. 
At the beginning of the COVID-19 crisis and the launch of the helpline, ALONE received 2-3 calls per week from people expressing suicidal ideation; in later weeks, this increased to 3-4 calls per day, something not seen before. Though many callers may already be in touch with mental health services, where this is not the case, ALONE refers them through the appropriate channels. ALONE staff are ASIST trained, and as well as its own services, have a partnership with the Samaritans who are following up with any older person who calls for support in this area.

Similarly, more older people are calling saying they are dealing with physical pain with $42 \%$ of support plan objectives for older people requesting support with physical health and personal care. Chronic conditions such as COPD and diabetes appear to be having a significant negative impact on quality of life during cocooning. Many callers have deferred engaging with health services because of anxiety about COVID-19; some have reported having fallen but not sought medical treatment or examination.

This suggests not only that the COVID-19 crisis and measures to curtail it are having a negative impact on older people, but that effects are exacerbated for the already vulnerable; the majority of calls come from those living alone ( $76 \%$ of callers between March 9th- June 21st), and those with chronic conditions, who may require assistance with ADLs and IADLs, may be more vulnerable to isolation.

\section{Key figures (March 9th - June 21st 2020 inclusive)}

- The ALONE helpline has received 24,529 calls

- ALONE has made 110,948 calls to older people providing active supports to Older People with an identified need

- 12,868 Older People being actively supported receiving regular assessment, support coordination, Telephone support calls, visits, health and wellbeing advice.

- $54 \%$ of callers are over 70 , among the cohort advised to cocoon

- $76 \%$ of callers live alone

- The most common area of need has been physical health including personal care followed by befriending, emotional and mental health. 


\section{Discussion}

The importance of social ties for the wellbeing of individuals of all age groups has gained prominence as the population adapts its behaviour in response to the COVID-19 pandemic. It is clear from this report that older adults enjoy good quality of life, and that a majority is socially integrated and never or rarely lonely. It also shows that an absence of social ties, and dissatisfaction with the quality and quantity of social contacts, is associated with poorer wellbeing. A substantial body of research already exists showing the negative impacts of loneliness on both physical and psychological wellbeing $(1,3)$ and more recently, excess mortality risk (12). Data from ALONE gathered since the introduction of measures such as cocooning and social distancing show a rise in loneliness and associated negative emotions. The reasons why it is more important now more than ever to quantify the prevalence of loneliness and social isolation among older adults are threefold. Firstly, we must identify those groups most at risk; secondly, we need to understand how loneliness and social isolation negatively impact wellbeing; and thirdly, we must take this knowledge and translate it to national and local policies to inform the development and roll-out of services and interventions to limit the damaging effects of the implementation of social distancing and cocooning. Public health should focus efforts to identify and intervene where possible to support the group most likely to be worst affected by the recent events. A planned project, led by TILDA in collaboration with ALONE and others, and funded by the Health Research Board, will address these and other issues relevant to the health and wellbeing of older adults affected by the COVID-19 pandemic. (23) 


\section{References}

1. Burholt $\mathrm{V}$, Scharf T. Poor health and loneliness in later life: The role of depressive symptoms, social resources, and rural environments. Journals Gerontol - Ser B Psychol Sci Soc Sci. 2014;69(2):311-24.

2. Park NS, Jang $Y$, Lee BS, Chiriboga DA. The relation between living alone and depressive symptoms in older Korean Americans: do feelings of loneliness mediate? Aging Ment Heal [Internet]. 2017;21(3):304-12. Available from: https://doi.org/10.1080/ 13607863.2015.1099035

3. Coyle CE, Dugan E. Social isolation, loneliness and health among older adults. J Aging Health. 2012;24(8):1346-63.

4. Mund M, Freuding MM, Möbius K, Horn N, Neyer FJ. The Stability and Change of Loneliness Across the Life Span: A Meta-Analysis of Longitudinal Studies. Personal Soc Psychol Rev. 2019;1-29.

5. Ward M, Layte R, Kenny RA. Loneliness, social isolation, and their discordance among older adults Findings from The Irish Longitudinal Study on Ageing (TILDA) [Internet]. Dublin: Trinity College Dublin; 2019. Available from: https://tilda.tcd.ie/ publications/reports/pdf/Report_Loneliness.pdf

6. Berg-Werger M, Morley JE. Loneliness and social isolation in older adults during the COVID=19 pandemic: Implications for gerontological social work. J Nutr Heal Aging. 2020;24(1):1-3.

7. Ward M, McGarrigle C. The Contribution of Older Adults to their Families and Communities. In: McGarrigle C, Donoghue O, Scarlett S, Kenny RA, editors. Health and Wellbeing: Active Ageing for Older Adults in Ireland Evidence from The Irish Longitudinal Study on Ageing. Dublin; 2017. p. 15-46.

8. Berkman LF, Syme S. Social networks, host resistance, and mortality: a nine-year follow-up study of Alameda County residents. Am J Epidemiol. 1979;109(2):186-204. 
9. O'Donoghue O, McGarrigle CA, Foley M, Fagan A, Meaney J, Kenny RA. Cohort Profile Update: The Irish Longitudinal Study on Ageing (TILDA). Int J Epidemiol. 2018;47(5):1398-1398I.

10. Kearney PM, Cronin H, O'Regan C, Kamiya Y, Savva GM, Whelan B, et al. Cohort profile: The Irish Longitudinal Study on Ageing. Int J Epidemiol. 2011;40(4):877-84.

11. Kenny RA, Whelan B, Cronin H, Kamiya Y, Kearney P, O'Regan C, et al. The Design of the Irish Longitudinal Study on Ageing. Dublin; 2010.

12. Whelan BJ, Savva GM. Design and methodology of the Irish Longitudinal Study on Ageing. J Am Geriatr Soc. 2013;61(SUPPL2):265-8.

13. Steptoe A, Shankar A, Demakakos P, Wardle J. Social isolation, loneliness, and all-cause mortality in older men and women. Proc Natl Acad Sci U S A [Internet]. 2013;110(15):5797-801. Available from: http://www.ncbi.nlm.nih. gov/pubmed/23530191\%0Ahttp://www.pubmedcentral.nih.gov/articlerender. fcgi?artid=PMC3625264

14. McHugh JE, Kenny RA, Lawlor BA, Steptoe A, Kee F. The discrepancy between social isolation and loneliness as a clinically meaningful metric: findings from the Irish and English longitudinal studies of ageing (TILDA and ELSA). Int J Geriatr Psychiatry. 2017;32(6):664-74.

15. Russell D. UCLA Loneliness Scale (Version 3): reliability, validity, and factor structure. J Pers Assess. 1996;66(1):20-40.

16. Wiggins RD, Netuveli G, Hyde M, Higgs P, Blane D. The evaluation of a selfenumerated scale of quality of life (CASP-19) in the context of research on ageing: A combination of exploratory and confirmatory approaches. Soc Indic Res. 2008;89(1):61-77.

17. Sexton E, King-Kallimanis BL, Conroy RM, Hickey A. Psychometric evaluation of the CASP-19 quality of life scale in an older Irish cohort. Qual Life Res. 2013;22(9):254959. 
18. Hyde $M$, Wiggins RD, Higgs $P$, Blane DB. A measure of quality of life in early old age: The theory, development and properties of a needs satisfaction model (CASP-19). Aging Ment Heal [Internet]. 2003;7(3):186-94. Available from: http://www.ncbi.nlm.nih. gov/pubmed/12775399

19. Karim J, Weisz R, Bibi Z, ur Rehman S. Validation of the Eight-Item Center for Epidemiologic Studies Depression Scale (CES-D) Among Older Adults. Curr Psychol. 2015;34(4):681-92.

20. O'Halloran AM, Kenny RA, King-Kallimanis BL. The latent factors of depression from the short forms of the CES-D are consistent, reliable and valid in community-living older adults. Eur Geriatr Med [Internet]. 2014;5(2):97-102. Available from: http://dx.doi. org/10.1016/j.eurger.2013.12.004

21. Radloff LS. A Self-Report Depression Scale for Research in the General Population. Appl Psychol Meas [Internet]. 1977;1(3):385-401. Available from: http://apm.sagepub. com.ezp2.lib.umn.edu/content/1/3/385.short

22. Cacioppo JT, Hawkley LC, Thisted RA. Perceived social isolation makes me sad: 5 -year cross-lagged analyses of loneliness and depressive symptomatology in the chicago health, aging, and social relations study. Psychol Aging. 2010;25(2):453-63.

23. COVID-19: TILDA project to survey and protect older people in Ireland. Health Research Board April 29th 2020 https://www.hrb.ie/news/covid-19-coronavirus/ coronavirus-news/article/covid-19-tilda-project-to-survey-and-protect-older-people-inireland/ 